\title{
A Study of Head and Neck Cancers Admitted at a Community Palliative Care Center: Madre de Amor Hospice Foundation from 1995-2008
}

\author{
Rhodora del Rosario-Ocampo
}

Madre de Amor Hospice Foundation

\begin{abstract}
Objectives. The main objective of this study was to describe the head and neck cancer cases referred to the Madre de Amor Hospice Foundation.

Method. A review of all the charts of head and neck cases referred to the hospice in the period 1995-2008 was done.

Results. All of the patients were adults with $50 \%$ in the $51-70$ year range. Majority (61\%) had a history of smoking. A mass in the neck was the most common first symptom felt. This was followed by pain, nose bleeding, dysphagia and nasal discharge. The most common site involved was the nasopharynx at $50 \%$ $(40 / 80)$ followed by the tongue, larynx and the maxilla. On entry to the hospice service, pain is by far the most common complaint followed by dysphagia, malnutrition, financial concerns and dyspnea. Pain control was achieved with the use of opioids but the more challenging symptom was dysphagia. More than half of the patients were under the hospice care for 6 months or less.
\end{abstract}

Conclusion. An earlier referral for hospice care is suggested to allow better care and more issues to be resolved. The creation of alternative way for feeding is strongly recommended before patients are sent home to allow for better nutrition and easier giving of medications. All of these will lead to a better quality of life.

Key Words: community-based hospice, palliative care, head and neck cancers

\section{Introduction}

Hospice comes from the Latin word "hospitium" meaning hospitality. Historically, these were houses of refuge for the sick, needy and dying during the Roman times. They were also found along the pilgrimage routes as a place to rest. Many of them were run by the religious.

Presented at the quarterly meeting of the Southern Tagalog Association of ENTs, February 2009, Tagaytay City, Cavite.

Corresponding author: Rhodora del Rosario-Ocampo, MD Madre de Amor Hospice Foundation

8817 Amethyst St, Los Baños Subdivision, Los Baños, Laguna 4030

Philippines

Telephone: +63495360644

Email: rhodora40@yahoo.com
Modern day hospice is credited to Dame Cicely Saunders, a nurse physician from the United Kingdom. She founded St. Christopher's Hospice in 1967 as a home for the dying. Dame Saunders put forth the concept of "total pain" meaning pain is not physical but has other components like emotional, psychosocial, spiritual and financial. Pain medications should be given round the clock instead of "as needed" for those suffering from cancer pain. The term was later changed to "palliative care" by Dr. Balfour Mount, a Canadian oncology surgeon and integrated into the mainstream of medicine. Today, palliative care is defined by the World Health Organization (WHO) as "an approach that improves the quality of life of patients and their families facing the problems associated with life threatening illness, through the prevention and relief of suffering by means of early identification and impeccable assessment and treatment of pain and other problems, physical, psychosocial and spiritual."1

In the Philippines, the hospice care movement began in 1992, with Dr. Catherine Lisondra-Krings. She trained in London at St. Christopher's and was eager to share her newfound knowledge here. She put up programs in University of the Philippines-Philippine General Hospital (UP-PGH) Department of Family Medicine and the Philippine Cancer Society. It has been seventeen years since and many hospice palliative care units have been set up including a fellowship training program at UP-PGH. To date, the availability of a hospice unit is paltry at best.

The Madre de Amor Hospice Foundation was organized in 1994 as a community-based hospice unit. It was founded by the parents of Sarah Katrina Adriano who, at 14 years of age, died of nasopharyngeal cancer. The vision of the Foundation is to build a strong community-based team of skilled caregivers complimented by a compassionate and dependable group of volunteers that will provide a holistic approach in the care and comfort of the terminally ill person in the last stages of their journey through life. Its mission is to provide palliative, emotional, spiritual aid and psychological support to the terminally ill as well as the elderly and chronically ill patients so that they face death with grace, peace and dignity and enable their families to cope up with the crisis. The community-based model was adapted by the Foundation because it was the most costeffective model for a community-based service. It did not 
need to put up a 24/7 facility. More importantly, the family was empowered to take care of their loved ones in their own home. This preserved patient autonomy and allowed them to die with dignity surrounded by family, friends and significant others. Today, this is the longest running community-based hospice in our country. It has served over 1000 patients and their families in Laguna. The Foundation has also assisted various organizations around the country to set up their own hospice programs.

Most of the cases seen in the Madre de Amor hospice are cancer patients with breast and lung cancer being the most numerous. This parallels the national trend. ${ }^{2}$ However, it was noted that the number of cases of head and neck cancers are slowly rising. These cases are particularly challenging for the hospice team. They have myriads of problems both physical and psychosocial. This paper aims to describe the head and neck cancer cases that the Madre de Amor hospice has seen from 1995-2008. It will identify the problems that most commonly affect them, their diagnosis, risk factors and outcomes. The data obtained will help improve the quality of care that hospice services are providing for these patients. Corollary to this, the Otorhinolaryngology (ORL) physician may be made aware of the problems that these patients experience when they are sent home. By doing so, the patients and their families may be more aware and prepared for the problems that lie ahead.

\section{Methods}

Cases of head and neck cancers from the period 19952008 were reviewed. The patients' characteristics and demographics were identified. The disease c haracteristics were described as to location, diagnosis, and treatment received. Finally, the functional characteristics of the patients with regards quality of life were listed.

\section{Results}

A total of 80 cases were identified out of the 784 cases in the period of 1995-2008. Of these, 49 (61\%) were male and 31 (39\%) were female. The patients' age ranged from 21-90 years. Table 1 shows the breakdown of cases in each age group. The most number of cases (25\%) were in the 51-60 years. $85 \%$ are in the $31-70$ years of age.

Presence of known risk factors were also considered (Table 2). Of the 80 cases, 49 (61.2\%) were cigarette smokers, 8 or $10 \%$ had a family history of cancer, $7(8.7 \%)$ reported exposure to chemicals, $3(3.8 \%)$ were betel nut chewers and 2 $(2.5 \%)$ were regular alcohol drinkers. No known risk factors were seen in 11 patients.

Table 3 shows the first symptoms that the patients felt. A mass in the neck was the most common complaint. This was followed by pain, nose bleeding, dysphagia and nasal discharge.
Table 1. The age range of patients seen with head and neck cancer $(\mathrm{N}=80)$.

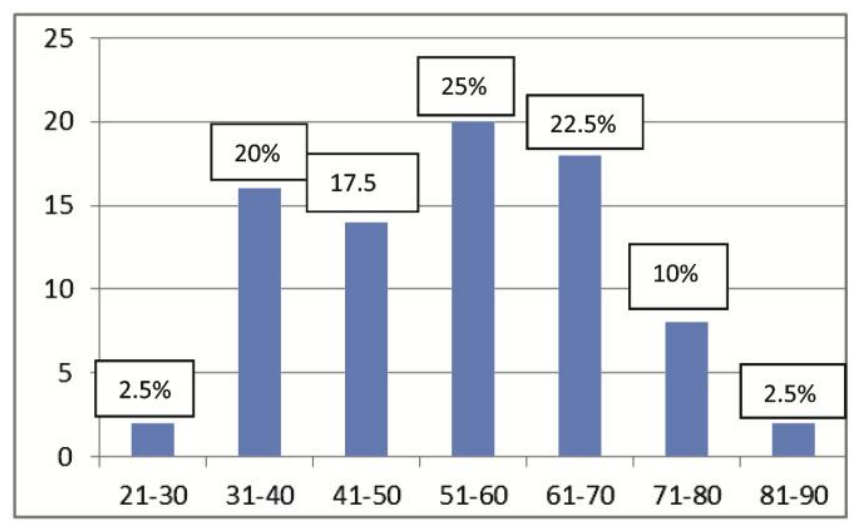

Table 2. Risk factors identified in patients seen $(\mathrm{N}=80)$.

\begin{tabular}{lcl}
\hline \multicolumn{1}{c}{ Risk Factor } & Number of patients & \% \\
\hline cigarette smoking & 49 & 61.2 \\
alcohol & 2 & 2.5 \\
betel nut chewing & 3 & 3.8 \\
exposure to chemicals & 7 & 8.7 \\
family history of CA & 8 & 10 \\
unknown & 11 & 13.8 \\
\hline
\end{tabular}

Table 3. Frequency of first symptoms noted by the patients $(\mathrm{N}=80)$.

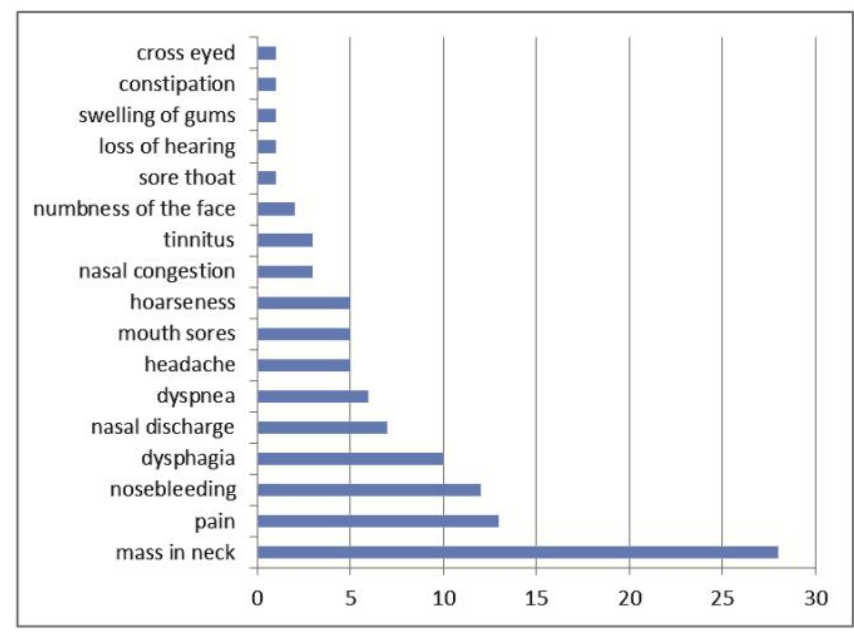

The specific areas in the head and neck that were affected by the cancer were also tabulated (Table 4 ). The most common area was the nasopharynx at 50\% (40/80). This was followed by the tongue, larynx and the maxilla. There were 3 cases wherein the biopsy of the neck node was adenocarcinoma but the primary was unknown. These patients were treated as head and neck cancers because the nodes were the biggest problem of these patients. They had no symptoms referable to their primaries. 
Table 4. The anatomic sites of the head and neck cancers of the patients $(\mathrm{N}=80)$.

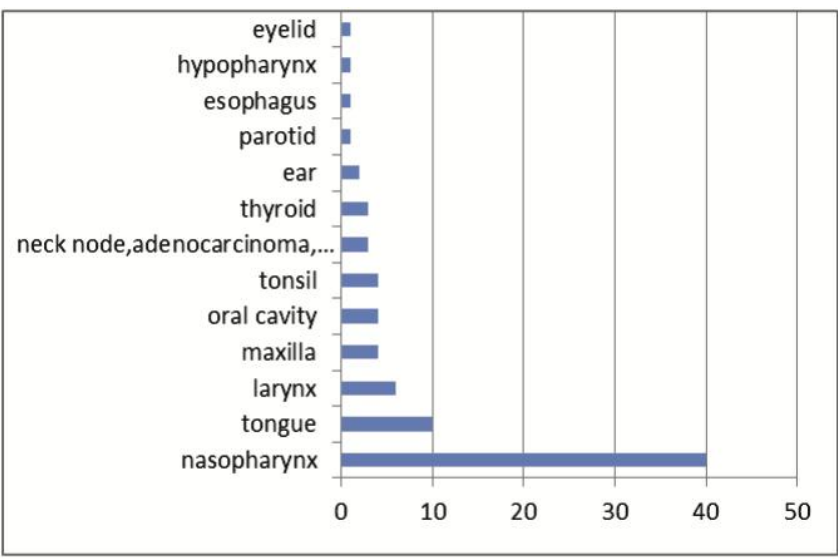

Table 5 shows the time interval between the first symptom and the diagnosis. About $55 \%$ of the patients were diagnosed in the first 6 months of the symptom. However, there were cases which took years before a diagnosis could be made. These cases corresponded to those with slow growing tumors like adenoid cystic carcinoma and those with relatively poor access to a specialist. The stages of the disease were not available in all cases. Unlike in countries with a well-entrenched palliative care system, referrals came mainly from the community rather than from the doctors. People who knew of the Madre de Amor hospice through a relative or friend who have been assisted by the service were the main source of referrals. This made the assessment and care tricky as often there were no medical abstracts or histopathology results available.

Table 5. The time interval from the first symptom and the diagnosis in months $(\mathrm{N}=80)$.

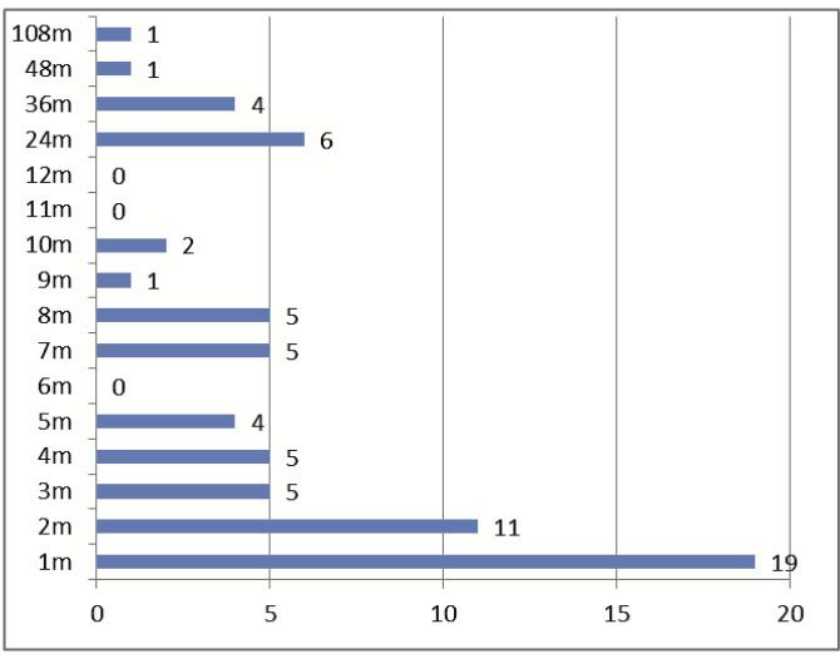

Most patients who received care did so within the first month after diagnosis (Table 6). Treatment options taken by the patients were then noted. Sixteen patients $(20 \%)$ had combination radiotherapy and chemotherapy, 12 (15\%) had radiotherapy alone, $10(12.5 \%)$ had surgery while $6(7.5 \%)$ had chemotherapy alone. There was no intervention at all in 40 patients $(50 \%)$. The reasons for this were mostly financial. Other explanations were superstitious beliefs, herbal/alternative options and fear of an operation. There was one patient with Nasopharyngeal Carcinoma (NPCA) who was in prison. Since there was no cancer facility nearby, he did not get any care. For many of the patients, even if there was a possibility of financial assistance for the treatment, the cost of going to and from the center was still untenable. This is exemplified in one case of maxillary carcinoma in a 40-year-old female. She lived in a far flung barrio and was very poor. At the time of the initial assessment by the service, her cheek had ballooned and the affected eye had blurring of vision. With adequate pain medications, she was still able to lead a productive life for 3 years before she died of lung metastasis.

Table 6. The time interval between diagnosis and treatment $(\mathrm{N}=80)$.

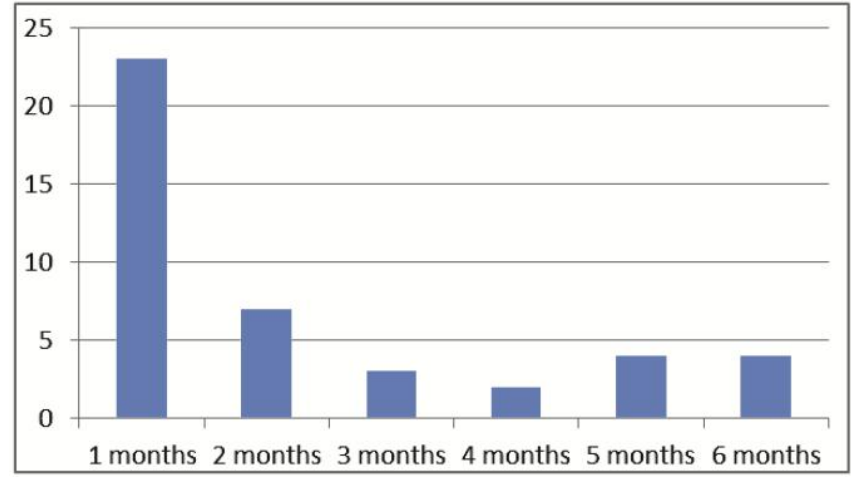

For those who did undergo some form of treatment, they all started within 6 months of the diagnosis. A 60-yearold male patient with maxillary cancer had surgery, chemotherapy and radiotherapy. In spite of all of these, the cancer progressed fast and there was distant metastasis within months. He was sent home with pain relievers and a disfigured face. This depressed him and led him to question if the money they had spent was worth it. In contrast to the earlier case, he lived for less than a year.

As part of the initial assessment, the symptoms that were bothering them are listed and prioritized. Table 7 shows the most common symptoms that the patients complained of. Pain is by far the most common followed by dysphagia, malnutrition, financial concerns and dyspnea.

These symptoms are commonly found in patients with head and neck cancers. Many of them were severely emaciated as feeding was an ongoing problem. No patient had an alternative mode of feeding like a tube gastrostomy. As such, nutrition and medication intake posed a challenge. Dyspnea was another concern as their nasopharynx were blocked, or there was an oral mass obstructing the airway. 
There were some with tracheostomies, but this too was being blocked by the growth of the tumor or were not cleaned regularly. All of them had no inner cannulas so a mucus plug could potentially be fatal.

Table 7. Common symptoms on entry to the hospice service $(\mathrm{N}=80)$.

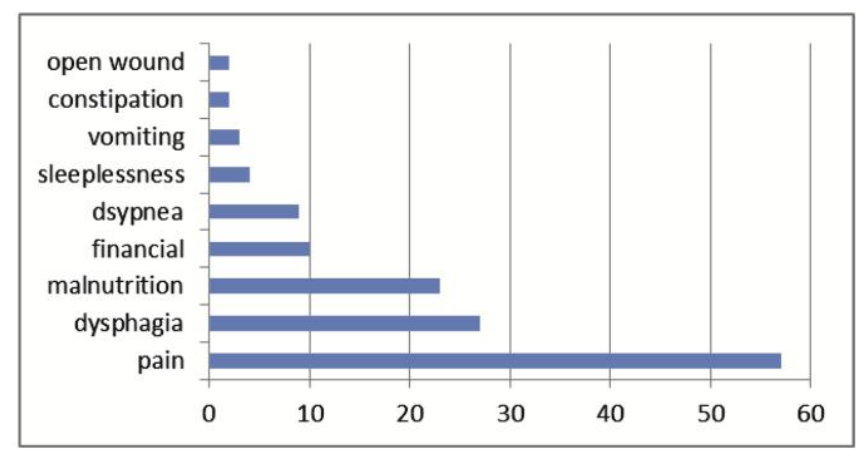

The period of care of these patients were tabulated in Table 8. Within one month, 18 (22.5\%) died while $68.7 \%$ died within 6 months. The short care period is because many of the cases are referred to the service in the very late stages. As such, the hospice team had to work fast and get the pain and symptoms under control so that the psychosocial and spiritual issues can be dealt with. Since most of the patients are male smokers, there is always a heavy guilt feeling of abusing one's body. Of these, $65 \%$ were less than 60 years and could have been still productive had they not gotten sick.

Table 8. Period care of patients with head and neck cancer $(\mathrm{N}=80)$.

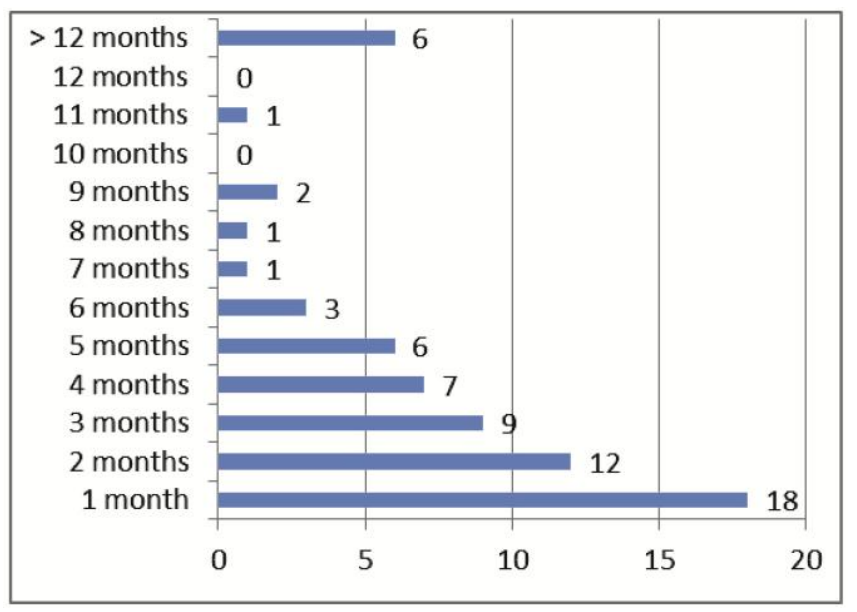

At the time of this data collection, 66 of the 80 patients had died already of which 60 died peacefully in their homes surrounded by their family while 6 died in the hospital. These six who went to a hospital did so because of diarrhea (2), pneumonia (1), dyspnea (1) and patient's wish to die in a hospital (1). The prisoner with NPCA was also brought to the hospital because it was government policy to do so.

\section{Discussion}

Palliative care is interdisciplinary care that provides support for the physical, emotional and psychological suffering of patients with an y advanced illness, regardless of age, diagnosis or life expectancy. ${ }^{3}$ It is particularly important in the care of head and neck cancers as they face an often relapsing course with periods of freedom from disease and symptoms interspersed with bouts of serious illness, debility and numerous physical symptoms including pain, dysphagia, weight loss, disfigurement, depression and xerostomia. ${ }^{4}$ The concept of suffering and its components are illustrated in Figure 1. This is the suffering that palliative care aims to prevent and relieve. Palliative care can be applied at any point in the disease continuum. It is just the amount of involvement that will differ. At the time of diagnosis, palliative care can help in the disclosure and communication with the patient and family. As the disease progresses and the prognosis get worse, palliative care will play a bigger role especially in pain and symptom management. (Figure 2). End of life care and bereavement support are just components of the continuum.

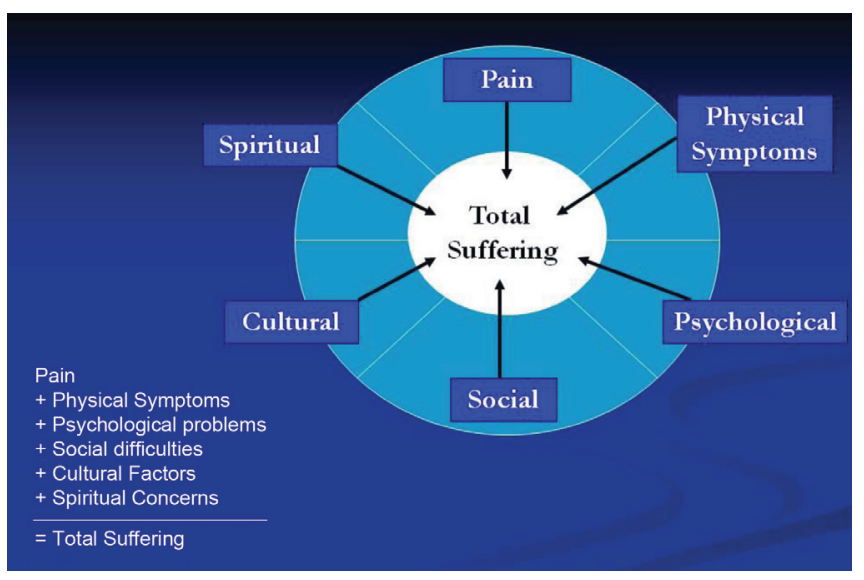

Figure 1. The Concept of Total Suffering Source: Doyle, D et al ${ }^{10}$

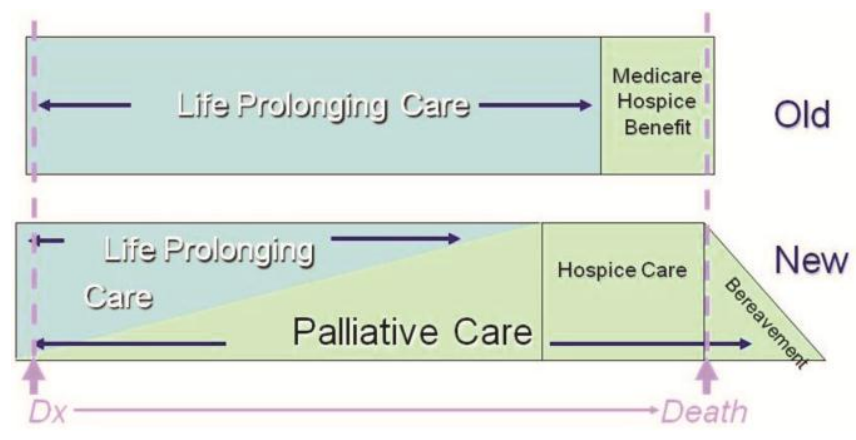

Figure 2. Models of palliative care.

Source: American Academy of Hospice and Palliative Medicine, 2010. 
Community-based centers are the cornerstone of palliative care access in resource poor settings. It is the most realistic model for achieving a significant coverage for two thirds of the world's terminally ill. ${ }^{5}$ Notable among these is the Kerala project in India called the Neighborhood Network in Palliative Care. This project utilizes trained volunteers to take care of its own terminally ill population. It has achieved an unprecedented success in the province of Kerala, one of the biggest provinces in southern India. It is currently the model for which most of the community-based palliative care centers are patterned. The Madre de Amor (MDA) hospice is modeled similarly. It utilizes trained volunteers who work side by side with the nursing and medical staff. Its coverage began in two towns, Los Baños and Bay, and has gradually spread to cover 23 out of the 30 municipalities of the province of Laguna. Volunteers from each town are recruited and trained. They are then assigned to care for patients in their locality.

Since its inception in 1994, the MDA hospice has taken cared of over 1000 patients and their families. The most number of cases are breast cancer followed by lung cancer. Head and neck cancer is the third most frequent. ${ }^{6}$ Pain and symptom control are of paramount importance in any palliative care unit. More so for those with cancers in the head and neck.7,8,9 Fortunately, the MDA hospice has morphine that is provided by the Department of Health. The problem is when the patient is no longer able to swallow. In these instances, morphine is given transrectal. Eating is frustrating as most did not have any alternative route for feeding. Even if the MDA hospice refers them for J peg insertion, they are either too thin already or have no money for the procedure. For the caregivers, this can be distressing as they see their loved one slowly waste away and not being able to do anything. The odor and overflow of saliva are also a concern for both the patient and the family. Often, they would not want to see visitors as they are embarrassed adding more to the loneliness and isolation that most cancer patients experience. In these instances, the care team gives intermittent intravenous fluids and encourages them to chew sugared ice in the hope that it may be absorbed though the buccal mucosa. For those with tracheostomies, a suction machine is lent to them. They are then taught how to clean their tubes properly. Oxygen supplementation is also given for dyspnea. The MDA hospice has oxygen tanks and gauges. A memorandum of agreement was done with a company that refills the tanks in exchange for a discounted price. For those who cannot tolerate lying down flat, hospital beds are lent out. Caregivers are taught proper care of open wounds using saline solution followed by application of powdered metronidazole for infected wounds. ${ }^{4}$ With the use of morphine, constipation is always there. As a rule, once patients are started on opioids, laxatives are given concomitantly. Financial concerns are always present in our patients. Referrals are given to government and nongovernment institutions who may be able to assist the patient. The MDA hospice does not give financial aid as the service is already free.

The International Association for Hospice and Palliative Care recently came out with the List of Essential Practices in Palliative Care in February 2012 (Table 9). ${ }^{10}$ The MDA hospice participated in the research towards the creation of this list. As the longest running community-based hospice in the country, the MDA hospice is recognized internationally for its efforts. As outlined in the table, most of the practices that the MDA hospice gives is included in this list. Still, there is still much to be done. On a national level, access to care is a huge problem. Palliative care units are scanty. When present, they have to compete fiercely for funding.

Table 9. IAHPC List of Essential Practices in Palliative Care(C)

Identify, evaluate, diagnose, treat and apply treatment and solution measures for:

\footnotetext{
Physical care needs:

Pain (all types)

Respiratory problems (dyspnea, cough)

Gastro intestinal problems (constipation, nausea, vomiting, dry mouth, mucositis, diarrhoea)

Delirium

Wounds, ulcers, skin rash and skin lesions

Insomnia

Psychological / Emotional / Spiritual care needs:

Psychological distress

Suffering of the relative and/or caregiver

Anxiety

Identify and evaluate - provide support and when possible, refer for diagnosis, treatment and solution measures for:

Physical care needs:

Fatigue

Anorexia

Anaemia

Drowsiness or sedation

Sweating

Psychological / Emotional / Spiritual care needs:

Spiritual needs and existential distress

Depression

Family / caregivers grief and bereavement issues

Other:

Care Planning and Coordination issues:

Identify the resources and support available and develop and implement a plan of care based on the patient's needs.

Provide care in the last days/weeks of life

Identify, evaluate and implement solutions to facilitate the availability and access to medications (with emphasis on opioids)

Identify the psychosocial / spiritual needs of self and other professionals involved in the care

Communication issues:

Communicate with patient, family and caregivers about diagnosis, prognosis, condition, treatment, symptoms and their management, and last days/weeks care issues.

Identify and set priorities with patient and caregivers.

Provide information and guidance to patients and caregivers according to available resources. Sensitize other health care professionals and workers about palliative care.
} 
Often they lose to programs with a more visible impact. Because the MDA hospice service is quite small, it can only reach a limited number of patients. Its goal is to reach out to all the municipalities of Laguna but financial support is lacking. Referrals are late such that patients often die within a few months. Public awareness is severely wanting. Sometimes, patients don't even want to be referred because of fear of death or a lack of understanding on what the hospice is all about and how it can help them. Referrals from doctors are lacking albeit MDA being present in the province of Laguna for the past eighteen years. ${ }^{6}$ However, this situation is not unique as this happens in many other countries too. This may be due to lack of understanding or belief in palliative care, poor prognostication, lack of communication skills to address end-of-life issues, loss of control, loss of income and lack of institutional standards for end-of-life care. ${ }^{11}$

\section{Conclusion}

This is a case review of head and neck cancer patients referred to the Madre de Amor Hospice from 1995-2008. Their presenting symptoms, treatment and complaints on entry to the service were tabulated and analyzed. The care that the Madre de Amor Hospice gave were also enumerated and explained. A basic understanding of palliative care and how it can be of help in the care of cancer patients is essential for all physicians, nurses and allied medical personnel involved in cancer care. This is more evident in the care of those with head and neck cancers. Impeccable pain control should be done, pain being the most common complaint of these patients. Morphine can easily control this. If one is not comfortable with opioids, then a referral should be made to a palliative care physician. Symptom control is also important. An early alternative mode of feeding should ideally be instituted early, before they become emaciated. Often, the pain is not only physical but also psychosocial and financial. Finally, awareness about palliative care should be increased not only in the medical field but to the public as well.

\section{Acknowledgment}

The author wishes to acknowledge the help of her staff at the MDA hospice led by Administrative Assistant Gina Cabrera and nurses Jenn Rualo and Ronald Aquino.

\section{References}

1. Davies E, Higginson I. The solid facts of palliative care. WHO Regional Office for Europe; 2004.

2. Arcellana-Nuqui EY. The Philippine handbook of clinical oncology, $2^{\text {nd }}$ ed. Manila: Philippine Society of Oncologists, Inc; 2001. pp. 41-57.

3. Clinical practice guidelines for quality palliative care, $2^{\text {nd }}$ ed. Pennsylvania: National consensus project for quality palliative care; 2009.

4. $\quad$ McPhee SJ, et al. Care at the close of life: evidence and experience. USA: McGraw Hill Medica; 2011. pp. 231-242.

5. Stjernsward J. Community participation in palliative care [Online]. 2005 [cited 2012 Jan]. Available from http://www.jpalliativecare.com.

6. Annual Reports 2009-2010. Madre de Amor Foundation.

7. Semple CJ, Sullivan K, Dunwoody L, Kernohan WG. Psychosocial interventions for patients with head and neck cancer: past, present, and future. Cancer Nurs. 2004; 27(6):434-41.

8. Hermann CP, Looney SW. Determinants of quality of life in patients near the end of life: a longitudinal perspective. Oncol Nurs Forum. 2011; 38(1):23-31.

9. Nelson R. Health behaviors linked to survival in head and neck cancer [Online]. 2009 [cited 2009 March]. Available from www.medscape.com/viewarticle/590603.

10. International association for hospice and palliative care. IAHPC List of essential practices in palliative care. Houston: IAHPC Press; 2012.

11. Doyle D, Woodroof R. Manual of palliative care, $2^{\text {nd }}$ ed. International Association of Hospice and Palliative Care [Online]. 2009 [cited 2012 Feb]. Available from http://www.hospicecare.com/manual/ IAHPCmanual.htm. 